\title{
AUTOMATIC RAIL EXTRACTION AND CELARANCE CHECK WITH A POINT CLOUD CAPTURED BY MLS IN A RAILWAY
}

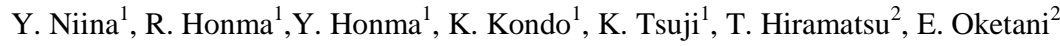 \\ ${ }^{1}$ Asia Air Survey Co.,Ltd., 1-2-2, Manpukuji, Asao-ku, Kawasaki-shi, Kanagawa, Japan \\ - (ysh.niina, ryh.honma, yic.honma, uuu.tsuji)@ajiko.co.jp \\ ${ }^{2}$ West Japan Railway Company, 4-24, Shibata 2-chome, Kita-ku, Osaka, Japan \\ - (takahiro-hiramatsu, eiichi-oketani)@westjr.co.jp@westjr.co.jp
}

Commission II, WG II/3

KEY WORDS: MLS, Railway, Rail Extraction, Clearance Check

\begin{abstract}
:
Recently, MLS (Mobile Laser Scanning) has been successfully used in a road maintenance. In this paper, we present the application of MLS for the inspection of clearance along railway tracks of West Japan Railway Company. Point clouds around the track are captured by MLS mounted on a bogie and rail position can be determined by matching the shape of the ideal rail head with respect to the point cloud by ICP algorithm. A clearance check is executed automatically with virtual clearance model laid along the extracted rail. As a result of evaluation, the accuracy of extracting rail positions is less than $3 \mathrm{~mm}$. With respect to the automatic clearance check, the objects inside the clearance and the ones related to a contact line is successfully detected by visual confirmation.
\end{abstract}

\section{INTRODUCTION}

Rail transportation system guided by fixed railway cannot avoid obstacles on railroads. Therefore, it is essential to detect objects, such as trees, signal, buildings and any structure (temporal and/or permanent) with incursion into the space moving through called "clearance gauge".

Currently, the presence or absence of obstacles inside the clearance gauge is confirmed with a device that the operator measures with like a wheelbarrow, or the operator visually checks from the front of the running train, but it is difficult to accurately perform over the entire track.

In this paper, we report about the automatically clearance checking algorithm by classifying Mobile Laser Scanning (MLS) point clouds in respect of railroad environment, and also for an automatic rail extraction necessary for this clearance check.

\section{RELATED WORK}

Prevailing LiDAR technology, classification methods of point clouds have been also focused on for several years. Enormous point data are acquired by airborne (ALS: Airborne Laser Scanning), terrestrial (TLS: Terrestrial Laser Scanning), and mobile (MLS) regardless manned or unmanned, various practical application are proposed for facility management. In the field of railway transportation, several cases of introduction or utilization of MLS are as follows.

Diaz Benito et al (2012) extract rail from a point cloud captured by ALS and TLS. In their experiment, points around rail track are classified into various classes, however a track geometry is not detected.

Oude Elberink et al (2013) describe the method to extract rail from a point cloud by MLS. They propose extraction algorithm consisting of two steps, first detecting rough position of rails based on knowledge about a railway, then specifying detailed position by fitting a general 3-D rail model. Finally, a line connected with extracted rail positions is smoothed by curve fitting. The accuracy of extracting rail positions is about $2 \mathrm{~cm}$. The problem is that it is necessary to apply the shapes of different models in a special rail such as a switch, and processing time is long.

Soni et al (2014) perform an experiment of detecting rail track geometry by using TLS. They apply the ICP algorithm (Besl et al (1992)) for matching CAD model rails and a point cloud to extract rails. Their results show a difference of about $2.5 \mathrm{~mm}$ between the truth and the extracted rail position.

Mikrut et al (2016) present an experiment of measuring rail track and checking clearance with two types of MLS. It concludes that clearance check can be performed with an accuracy of $2 \mathrm{~cm}$ to $3 \mathrm{~cm}$, but it does not mention the details of extracting rails.

Zhou et al (2017) perform an automatic clearance inspection of railway tunnel with MLS point cloud. They conclude that the accuracy of detecting rails is within $3 \mathrm{~cm}$ and its method can meet the requirement of clearance inspection.

In this paper, we developed a high speed and high precision rail detection algorithm. To verify the accuracy, a comparison between the rail measurement data with track geometry car that can acquire high precision track measurement data and automatic extracted rail data by the proposed algorithm is executed continuously in a $5 \mathrm{~km}$ section. Additionally, in the case of the clearance check, we propose an algorithm to detect the object within a clearance gauge excluding overhead lines and catenary equipments (hereinafter called "catenary equipments" collectively) in the electricity section. 


\section{ALGORITHM}

\subsection{Automatic rail extraction}

Figure 1 shows the criteria for the clearance gauge in West Japan Railway Company (This is called "JR-West") for a conventional line. In order to detect an object inside its range using by a 3-D point cloud space, it is necessary to accurately set the frame of this clearance, but that frame position is defined on the bases of the track center line and rail position. Therefore, we tried to develop an algorithm of extracting rail position from the point cloud, prior to further processing.

Figure 2 shows the overall processing of the algorithm of rail position extraction. In this proposed method, the rail position is extracted at a constant interval $\Delta D$.

Firstly, a point cloud is clipped with a width $\mathrm{L}$ in every $\Delta D$ along the track with a trajectory derived from MLS.

Secondary, the clipped point cloud of a width $\mathrm{L}$ is projected to the plane that is vertical to the trajectory direction. Next, the position of the gauge corner (hereinafter, this is called "GC"), that is the inside corner of a rail head, is extracted by matching the shape of the ideal rail head with respect to the projected point cloud by adopting the ICP algorithm. The reason for using the shape of rail head instead of whole shape is avoiding miss matching of GCs' height due to a rail wear.

After extracting GCs, the point of the track center, the gauge (distance between bilateral rails) and the cross level (height difference between bilateral rails) are calculated by extracted right GC and left GC (Figure 3). Finally, rail geometry and track center line are defined as connected each GC positions and each points of track center sequentially.

In this experiment, we set parameters for clipping range on the projection of point cloud as $L=0.2 \mathrm{~m}$ and $\Delta D=1.0 \mathrm{~m}$, considering the influence of steep curves and gradients of track geometry.

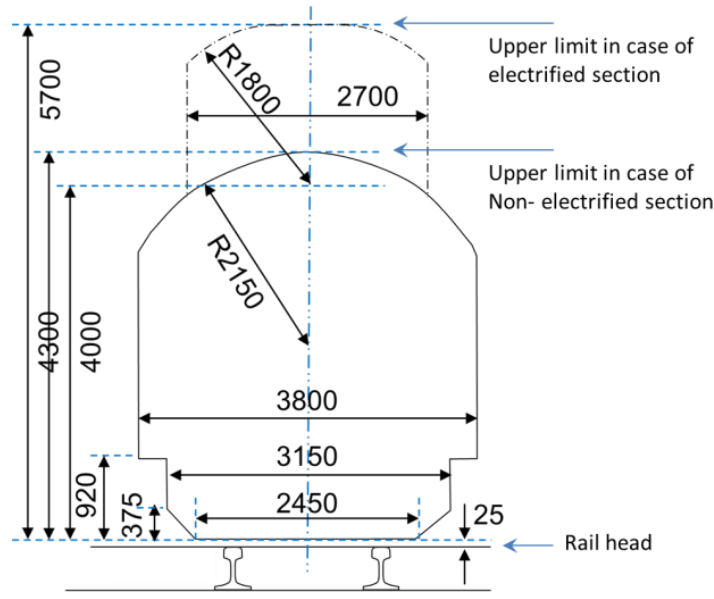

Figure. 1 The clearance gauge of a conventional line in JR-West

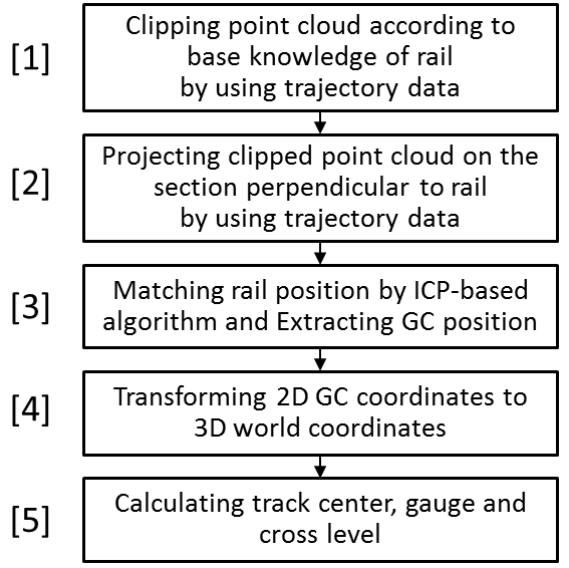

[1] Clipping

[2] Projecting
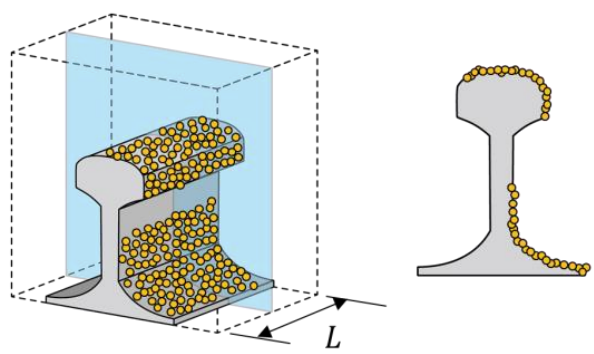

[3] Matching
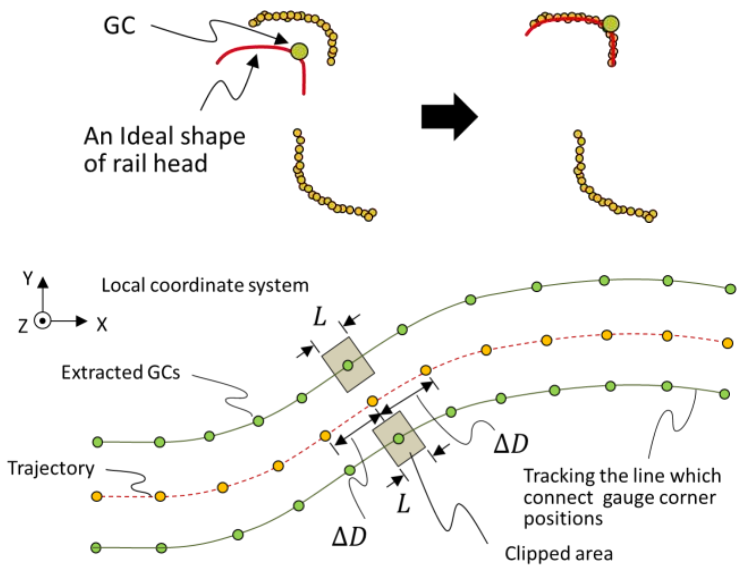

Figure 2. The overall algorithm of the rail extraction

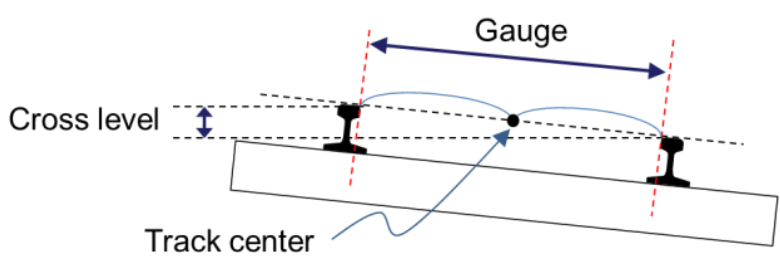

Figure 3. Track center, gauge and cross level

\subsection{Automatic clearance check}

Detection of objects inside the clearance gauge is executed by fitting the virtual frame of the clearance gauge to the 3-D point cloud space. The position of the clearance gauge is automatically derived from track center line extracted by the method of Section 3.1 and checking the presence or absence of points in the frame. 
Figure 4 shows the clearance frame extruded along the extracted rail center line with distance $\Delta D$.The points within the space surrounded by the surfaces are classified as obstacle objects. This process is performed in sequence, then it is possible to confirm the clearance check in all sections.

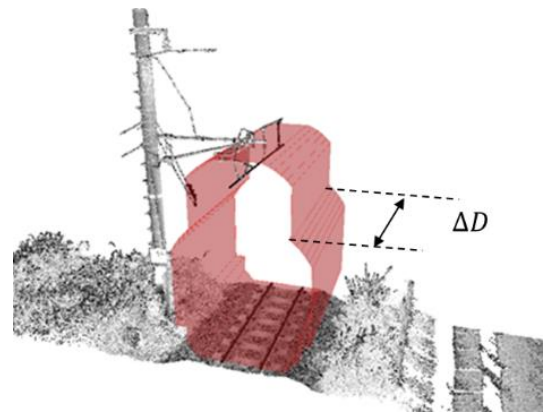

Figure 4. The image of automatic clearance check

A clearance gauge in a curve section is to expand the left and right widths, and in JR-West it is defined as follows.

$$
\mathrm{W}=\frac{23100}{R}
$$

Where

$$
\begin{aligned}
& W=\text { expansion width }[\mathrm{mm}] \\
& R=\text { curve radius }[\mathrm{m}]
\end{aligned}
$$

We can set $R$ to the value defined in the facility register for calculating $W$, however in this method we apply the one that is calculated from the geometry of rail center line by extracted rails automatically. Curve radius is calculated by using the center position of the point of interest and the center position of the part $50 \mathrm{~m}$ away in the front and back.

In case of an electrified section in a railway, catenary equipments are inevitably contained within the clearance gauge, therefore it is necessary to ignore them while checking clearance.

Our proposed method can exclude the points related to catenary equipments from clearance judgment by PCA (Principal Component Analysis), RANSAC (RANdom SAmple Consensus) and region growing method. Figure 5 shows that flow.

\section{START}

Read information of center line

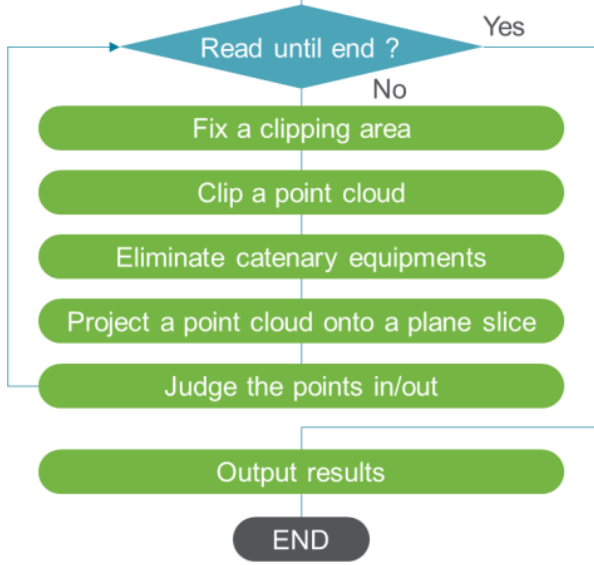

Figure 5. The overall algorithm of the clearance check

\section{DATA ACQUISITION}

In this experiment, we attempted to acquire a point cloud around the rail track by MLS on a bogie pulled by a motor car. Table 1 shows the specification of the MLS and Figure 6 shows the condition of this measurement test. Figure 7 shows an example of the obtained point cloud. As a result of visual observation of the point cloud, we found that not only the track but also many structures and facilities such as station platforms, tunnels, signals, bridges, indicators and contact lines were clearly acquired.

\begin{tabular}{c|c}
\hline Product name & Pegasus: Two \\
\hline Manufacturer & Leica Geosystems \\
\hline Laser scanner & Z+F PROFILER $\AA 9012$ \\
\hline $\begin{array}{c}\text { Data acquisition } \\
\text { rate }\end{array}$ & $\begin{array}{c}1016 \text { million pixel } / \mathrm{s} \\
\text { (Rotation speed: } 200 \mathrm{~Hz})\end{array}$ \\
\hline Point density & $\begin{array}{c}1600 \mathrm{pts} . \mathrm{m}^{2} \\
(@ 10 \mathrm{~m}, @ 10 \mathrm{~m} / \mathrm{s})\end{array}$ \\
\hline Distance & $0.3 \mathrm{~m}-119 \mathrm{~m}$ \\
\hline Relative accuracy & About $0.2 \sim 0.5 \mathrm{~mm}(@ 10 \mathrm{~m})$ \\
\hline Absolute accuracy & 2cm $($ Open sky condition) \\
\hline Table 1. Specification of MLS in this experiment
\end{tabular}

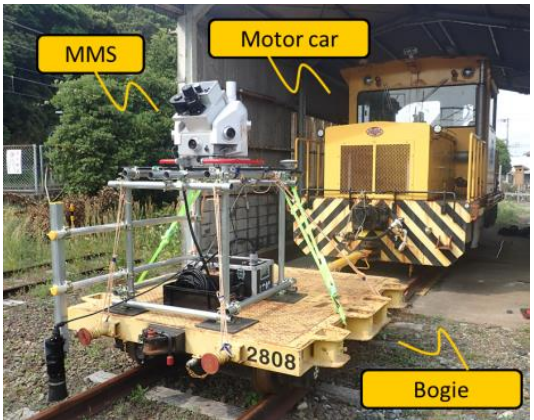

Figure 6 . The condition of this experiment
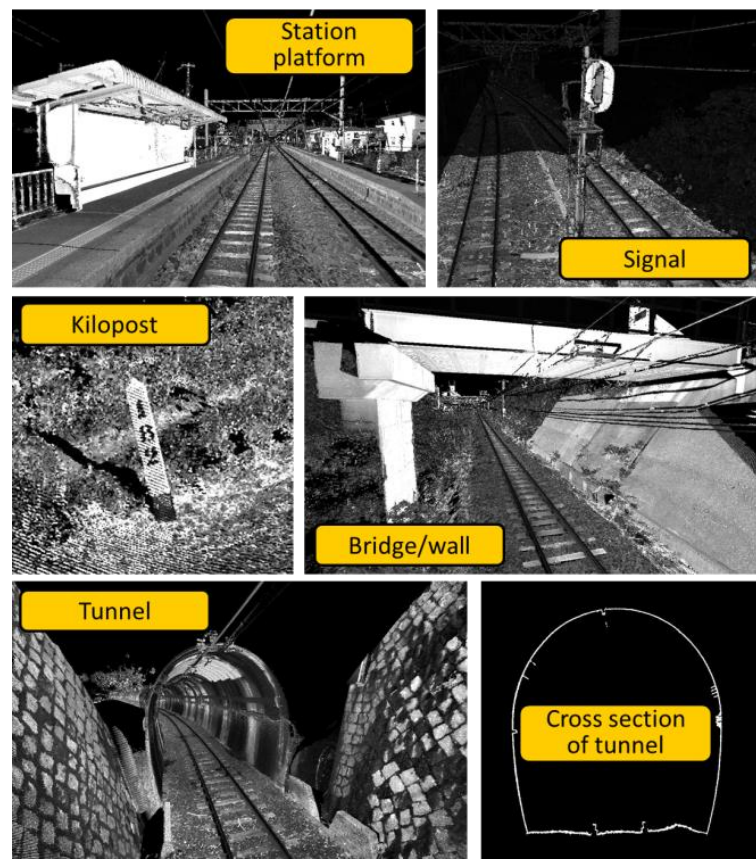

Figure 7. An example of the obtained point cloud by MLS

\section{EVALUATION}

At first, we extracted rail positions with $\Delta D=1.0 \mathrm{~m}$ and $L=0.2 \mathrm{~m}$ in various track geometry, further we checked the overall 
condition of the rail extraction by physical confirmation. Figure 8 and Figure 9 indicate an example of the rail extraction.

As a result of the confirmation, the rail position could be extracted within about $10 \mathrm{~mm}$ error in many sections.

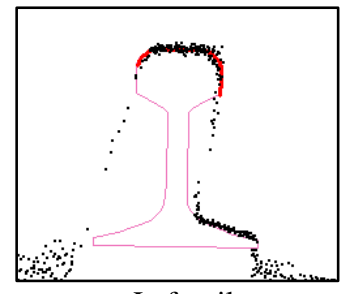

Left rail

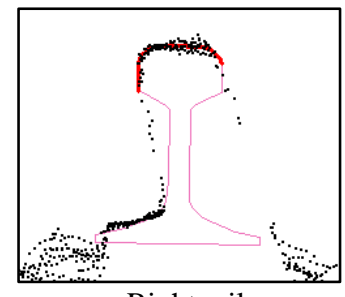

Right rail
Figure 8. An example of the rail extraction (cross section)

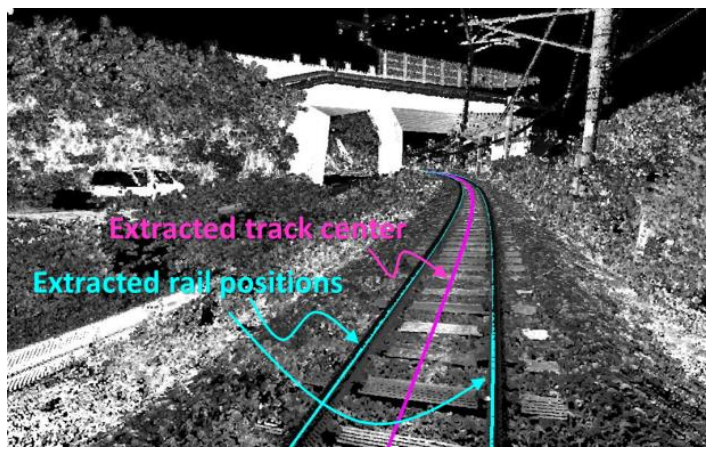

Figure 9. An example of the rail extraction (3-D)

In order to perform further quantitatively evaluation of the accuracy of the extracted rail positions, we attempted to compare with the calculated gauges and the cross levels from the MLS point cloud and measured ones with track geometry car that belongs to JR-West in the section of $5 \mathrm{~km}$.

For this evaluation, it is necessary to select a section where the GNSS reception status of MLS is good for the purpose of matching both kiloposts, and it is also desirable to evaluate the difference due to various line geometries. Figure 10 indicates the slopes and curves of test section that satisfies the above conditions.

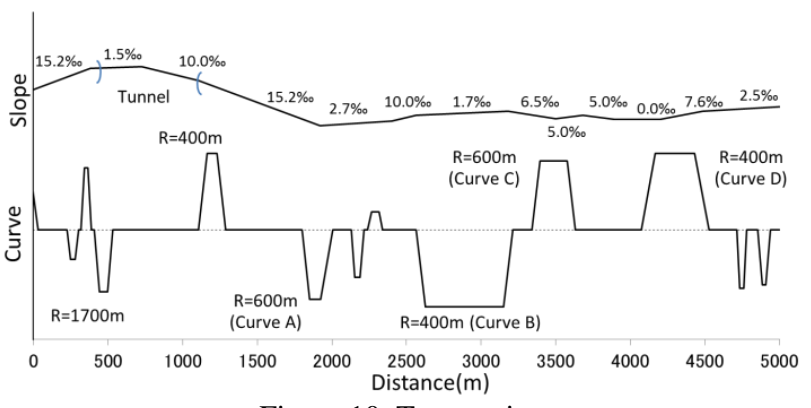

Figure 10. Test section

Figure 11, Figure 12 and Table 2 show the result. It is found that the standard deviation of the gap between calculated values by MLS and measured values by track geometry car for gauges and cross levels are less than $3 \mathrm{~mm}$ though some large differences can be seen. Hence, we conclude the proposed algorithm can extract the rail positions with good accuracy as the entire test section. On the other hand, there are slightly larger gaps of $5 \mathrm{~mm}$ to $10 \mathrm{~mm}$ in the curve sections.

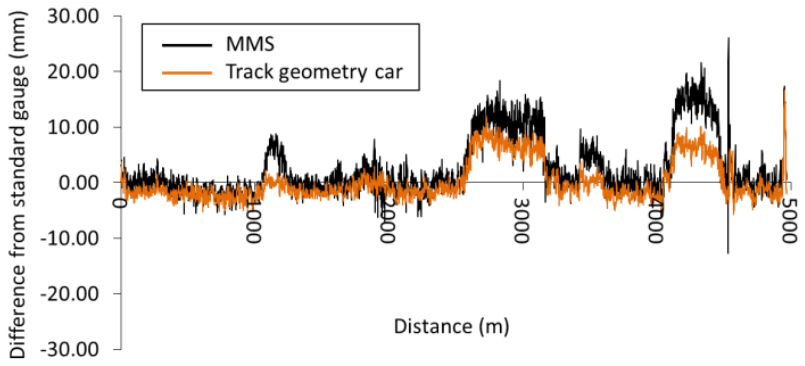

Figure 11. Comparing calculated gauge and measured one

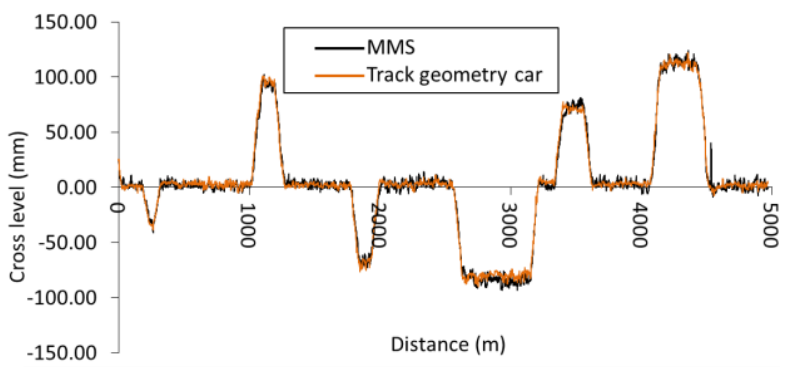

Figure 12. Comparing calculated cross level and measured one

\begin{tabular}{|c|c|c|}
\hline & \multicolumn{2}{|c|}{$\begin{array}{c}\text { Gap between calculated values by MMS } \\
\text { and measured values by special car }\end{array}$} \\
\hline & Standard deviation & Max difference \\
\hline Gauge & $2.4 \mathrm{~mm}$ & $29.0 \mathrm{~mm}$ \\
\hline Cross level & $2.9 \mathrm{~mm}$ & $40.4 \mathrm{~mm}$ \\
\hline
\end{tabular}

Table 2. Result of the gap of gauge and cross level

An example of cross section of rail extraction position is shown in Figure 13. The rail position is detected in many sections regardless of the linear line and curved section ([a][b]). On the other hand, there are some parts where the rail is detected at an inappropriate position because the variation of the point group on the top of the rail head is large ([c]). Additionally, at the railroad crossing it is completely failed to extract the rail ([d]), therefore it is necessary to apply another algorithm at the point.

With respect to the automatic clearance check, we also performed the processing with $\Delta D=1 \mathrm{~m}$. As a result of visual confirmation, it was found that the points inside the clearance gauge and points related to catenary equipments could be successfully detected. Figure 14 shows an example of the extraction situation.

Table 3 shows the result of comparing the average value of the curve radius calculated in every $1 \mathrm{~m}$ with the method using three center positions at $50 \mathrm{~m}$ intervals and the nominal value of the curve radius in four curve sections included in the test section. Although the gap from the nominal value is about $4 \%$ in the curve $\mathrm{C}$, the difference in the expanding amount of the clearance gauge calculated by Eq. (1) is about $1.4 \mathrm{~mm}$, which is considered to have less influence.

The relationship between distance and curve radius in the curve A is shown in Figure 15. It draws a smooth line without inappropriate values. 


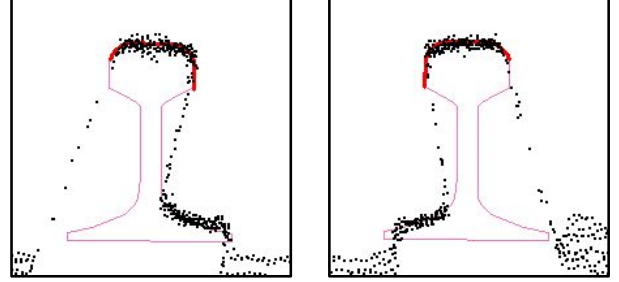

[a] Appropriate extraction (linear section)

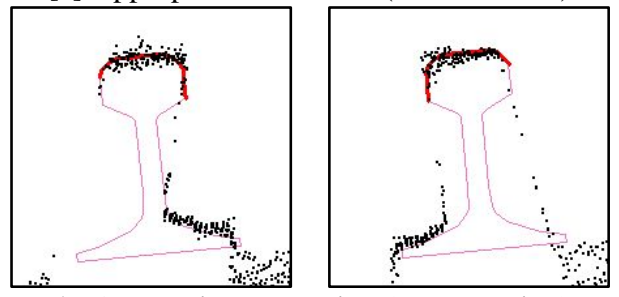

[b] Appropriate extraction (curve section)

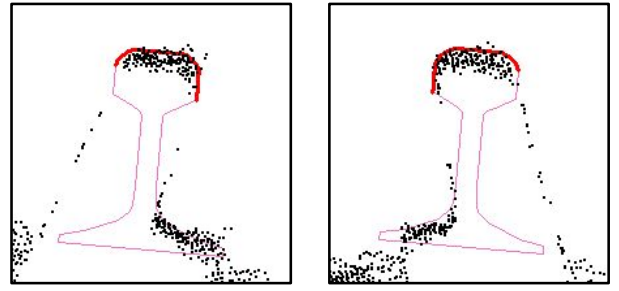

[c] Inappropriate section (curve section)

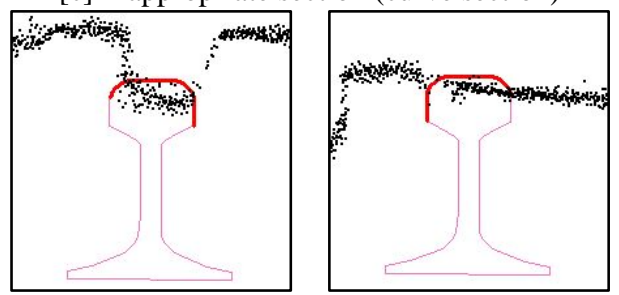

[d] Incorrect extraction (railroad crossing)

Figure 13. Examples of extracting rails

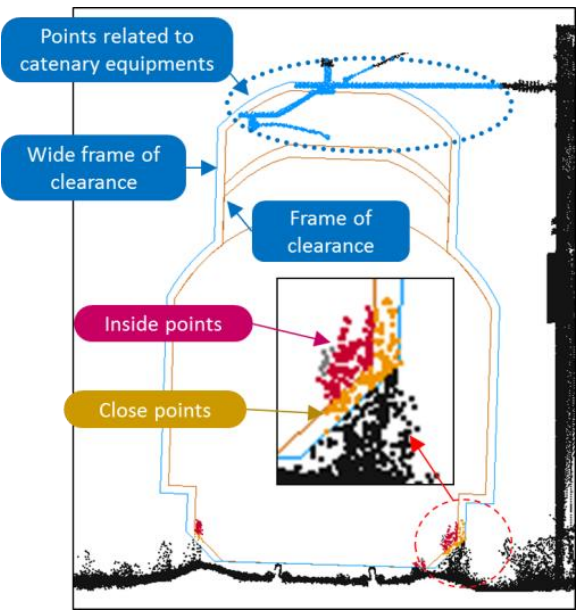

Figure 14. An example of extracting points inside the clearance and points related to catenary equipments

\begin{tabular}{|c|c|c|c|c|}
\hline \multirow{2}{*}{ No. } & \multicolumn{2}{|c|}{ Nominal value } & \multicolumn{2}{c|}{ Calculated value } \\
\cline { 2 - 5 } & $\begin{array}{c}\text { Curve } \\
\text { radius }\end{array}$ & Dist. & $\begin{array}{c}\text { Mean curve } \\
\text { radius }\end{array}$ & $\begin{array}{c}\text { Mean val./ } \\
\text { Nominal val. }\end{array}$ \\
\hline Curve A & $600 \mathrm{~m}$ & $205 \mathrm{~m}$ & $614 \mathrm{~m}$ & 1.02 \\
\hline Curve B & $400 \mathrm{~m}$ & $646 \mathrm{~m}$ & $402 \mathrm{~m}$ & 1.00 \\
\hline Curve C & $600 \mathrm{~m}$ & $290 \mathrm{~m}$ & $623 \mathrm{~m}$ & 1.04 \\
\hline Curve D & $400 \mathrm{~m}$ & $455 \mathrm{~m}$ & $398 \mathrm{~m}$ & 0.99 \\
\hline
\end{tabular}

Table 3. Comparison of automatically calculated curve radius and nominal value of curve radius

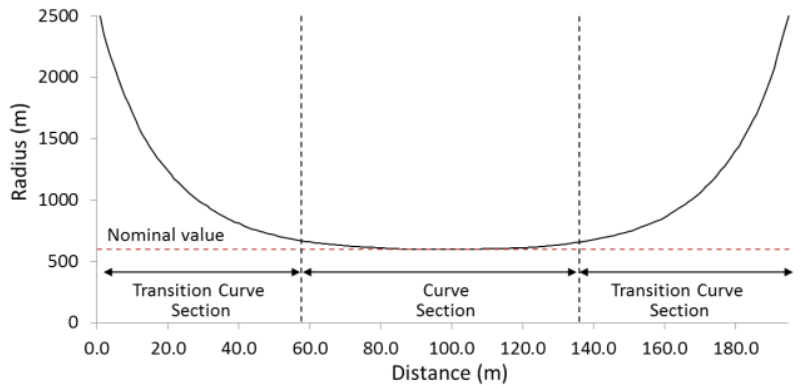

Figure 15. The relationship between distance and curve radius in curve $\mathrm{A}$

\section{CONCLUSION}

In this paper, we discussed the algorithms for automatic rail extraction and clearance check on rails with MLS point cloud. As a result of the verification, for gauges and the cross levels, the standard deviation of the gap between the calculated values by this algorithm with MLS point cloud and the highly accurate measurement values was less than $3 \mathrm{~mm}$, which can be said to be a good result. In addition, clearance check was also successful by visual inspection.

MLS can be effective tool not only as a clearance checking device but as a monitoring system for facilities of a railway if MLS point cloud is able to detect secular changes of the shape of facilities that are difficult to be found with physical inspection.

In the future, we have a plan to further develop MLS for railway operations.

\section{REFERENCES}

Besl P. and McKay N.D., 1992. A method for registration of 3D shapes, IEEE Trans. On PAMI, 14(2), pp.239-256.

Díaz Benito D. et al., 2012. Automatic 3D modelling of train rails in a lidar point cloud, MSc thesis, University of Twente Faculty of Geo-Information and Earth Observation (ITC).

Mikrut S., Kohut P., Pyta K., Tokarczyk R., Barszcz T. and Uhl T., 2016. Mobile Laser Scanning Systems for Measuring the Clearance Gauge of Railways: State of Play, Testing and Outlook, Sensors, 16(5), 683.

Oude Elberink S., Khoshelham K., Arastounia M., Díaz Benito D., 2013. Rail track detection and modelling in mobile laser scanner data, ISPRS Annals of the Photogrammetry. Remote Sensing and Spatial Information Sciences, Volume II-5/W2, pp. 223-228.

Soni A., Robson S. and Gleeson B., 2014. Extracting rail track geometry from static terrestrial laser scans for monitoring purposes, The International Archives of the Photogrammetry, Remote Sensing and Spatial Information Sciences, Volume XL5, pp.553-557.

Zhou Y., Wang S., Mei X., Yin W., Lin C., Hu Q and Mao Q, 2017. Railway Tunnel Clearance Inspection Method Based on 3D Point Cloud from Mobile Laser Scanning, Sensors, 17(9), 2055. 